\title{
Damage in fibreglass composite laminates used for pipes.
}

\author{
Juan S. León B. ${ }^{1,}$ a , O.A González-Estrada ${ }^{2, b}$ and A. Pertuz ${ }^{3, c}$ \\ 'Universita degli studi di Salerno, Italy \\ ${ }^{2}$ GIC, School of Mechanical Engineering, Universidad Industrial de Santander, Ciudad \\ Universitaria, Bucaramanga, Colombia. Orcid: 0000-0002-2778-3389. \\ ${ }^{3}$ GIEMA, School of Mechanical Engineering, Universidad Industrial de Santander, Ciudad \\ Universitaria, Bucaramanga, Colombia.
}

aj.leonbecerra@studenti.unisa.it, bagonzale@uis.edu.co, capertuzc@uis.edu.co Keywords: continuum damage mechanics, finite element, composite pipe, fiberglass, damage
evolution.

\begin{abstract}
In this work, we present a model for the initiation and evolution of damage for a composite fibre-reinforced pipe used in the Oil \& Gas industry, based on a commercially available pipe. A continuum damage mechanics model was employed to determine the initiation and evolution of damage. This model was implemented using finite element analysis to investigate the performance of the commercial composite pipe. Initially, the material properties were obtained from experimental data and fitting with static structural simulations. Then, FE simulations with damage were performed, considering three different boundary conditions: open, closed (pressure-vessel type) and fixed ends, the load considered was internal pressure. Results showed differences not only in the stress distribution but on the damage initiation and evolution along the geometry of the pipe. These differences in the damage initiation and propagation can be explained as the result of different axialhoop stress ratio.
\end{abstract}

\section{Introduction}

Composite pipelines have numerous competitive advantages over metal pipelines in Oil \& Gas sectors [1]. The costs of installation, operation and maintenance are reduced because they are sold in rolls, requires less personnel and equipment for installation, do not use welding, coatings or X-rays and, most importantly, do not present corrosion. However, the evaluation of structural integrity and the remaining life is more complex than in steel, due to the anisotropic properties of the reinforcing layer.

In this work, we consider the composite pipe as an elastic material coupled with damage, a model which determines the initiation of the damage and the corresponding law of evolution is employed. First, the determination of the stress and strain field has been obtained, then a continuum damage model is used to account for the initiation and progression that describes the nonlinear response of the reinforcement layer for internal pressure. The influence of axial stress in the damage is investigated to determine the relationship between boundary conditions at initiation and propagation of damage.

The stresses generated in the pipe depend on the loads, the geometry, the material properties and the boundary conditions [2], [3]. The loads are usually defined in the design stage, the geometry is a circular profile with a specific thickness, the material properties are given by the composite material configuration and the boundary conditions depend on the installation setup. The most typical boundary conditions for internal pressure pipes are: fixed, closed and open. In the closed-end condition, the pressure acts on the lateral faces, which creates longitudinal stresses, in isotropic pipes these are given by $\sigma_{a}=\operatorname{Pr} / 2 t$ [3]. In the fixed -end conditions, the $x$-displacement is restricted at ends such that longitudinal stresses are generated, with a value of $\sigma_{a}=v \operatorname{Pr} / t$, related to the Poisson effect 
[3]. Finally, in the open-end condition ideally there are not longitudinal stresses because very elastic supports exist at the end. Hoop stresses are given by $\sigma=\operatorname{Pr} / t$ [3]. However, in anisotropic cylinders the stress distribution is not as simple as those from the equations aforementioned.

Xia et al. [4], based on the anisotropic tridimensional elasticity, give an exact solution for the stresses and strains of an internal pressure pipe. Sun et al [5] have developed a stress analysis which follows the Lekhnistskii formalism, that uses an homogenization method to describe the response of hollow composite cylindrical structures consisting of multiple layers of different anisotropic materials, subjected to different loads such as pressure, axial force, torsion, shear and bending.

While there have been developed analytical methods to solve exactly the stress distribution on a multilayer composite pipe, numerical methods are still used due to their simplicity and accuracy of the results, mostly because no assumptions or simplifications are made. General 3D stress distributions are obtained, and in problems concerning damage, an analytical analysis would be difficult to perform [6], [7].

If the stresses are known, it is possible to apply a failure criterion to determine if the structure does not sustain irreversible damage. Nevertheless, if the load is increased beyond that point, damage initiates. A damage progression must be done to know the functional failure of a structure. Damage is responsible for the non-linear response of pipes [8], and it can be difficult to treat damage in composites due to different mechanisms, scales and analysis approach used. Ferry et al. [8] show that pipes exhibit varying types of damaged elastoplastic behaviour depending on stress ratio axial /hoop stress, which changes for the different BCs as stated above. The extent of damage and plastic phenomena are responsible for non-linearity on stress-strain curves. They show by micrographic analysis that microcracking is the main damaging process.

In [9], the authors show that an important parameter for the failure evolution is stiffness degradation. A progressive failure analysis is made using continuum damage mechanics (CDM) for a composite pressure vessel with an aluminium layer. An explicit finite element method is used, which proved to be more convenient due to the convergence issues of the implicit method.

Almeida et al. [10] proposed a damage model for a carbon-fibre reinforced composite pipes under external pressure. A non-linear geometric analysis was performed based on the arc-length method to predict the buckling load. Also, a damage model using CDM was developed to evaluate de gradual stiffness degradation, showing good agreement between experimental and numerical results.

\section{Finite element and damage model}

Typically, a composite pipe for oil transport is formed by an internal thermoplastic pressure barrier, an adhesion layer, a laminate which may be glass fibre reinforced with an epoxy matrix and on the outside, is covered by a wear resistance thermoplastic layer. The study was made on a Fiberspar@ pipe with an internal diameter of the HDPE layer equal to 2 inches $(50.8 \mathrm{~mm})$, the internal diameter of the epoxy laminate is $55.78 \mathrm{~mm}$, the internal diameter of the exterior HDPE is 59.79 and the outer diameter is $64.77 \mathrm{~mm}$.

For the first ply failure (FPF), the Hashin's criterion [11] was used. It has two types of failure mechanisms that are considered: in the fibre and in the matrix. Two expressions are used for identifying each failure by considering separately the traction and compression. Above the FPF load, the stiffness of the laminate will change and a more complex analysis must be performed which is called progressive damage or failure. Due to the ease of implementation and relatively good results [12], a CDM method was chosen for the modelling of damage in the multilayer composite pipe. The 
CDM method chosen is presented in Matzenmiller et al. [13]. Damage change the material stiffness $C$ in function of an internal variable $C(D)$ by considering the evolving and irreversible conditions of the damage. The response of a damaged solid is a nonlinear function of the applied load and depends on the history load.

\section{Experimental procedure}

For the evaluation of the mechanical properties of the composite laminate, a tensile test was performed on a UMT Bionix tensile machine, using a strip of a longitudinal cut of the composite pipe and, then, compared to a numerical model, Figure 1 . Determination of the damage model parameters was done by tension and compression tests (ASTM D3039 and D6641) using specimens produced by open hand lay-up moulding, two types were employed: $0^{\circ}$ and 90.
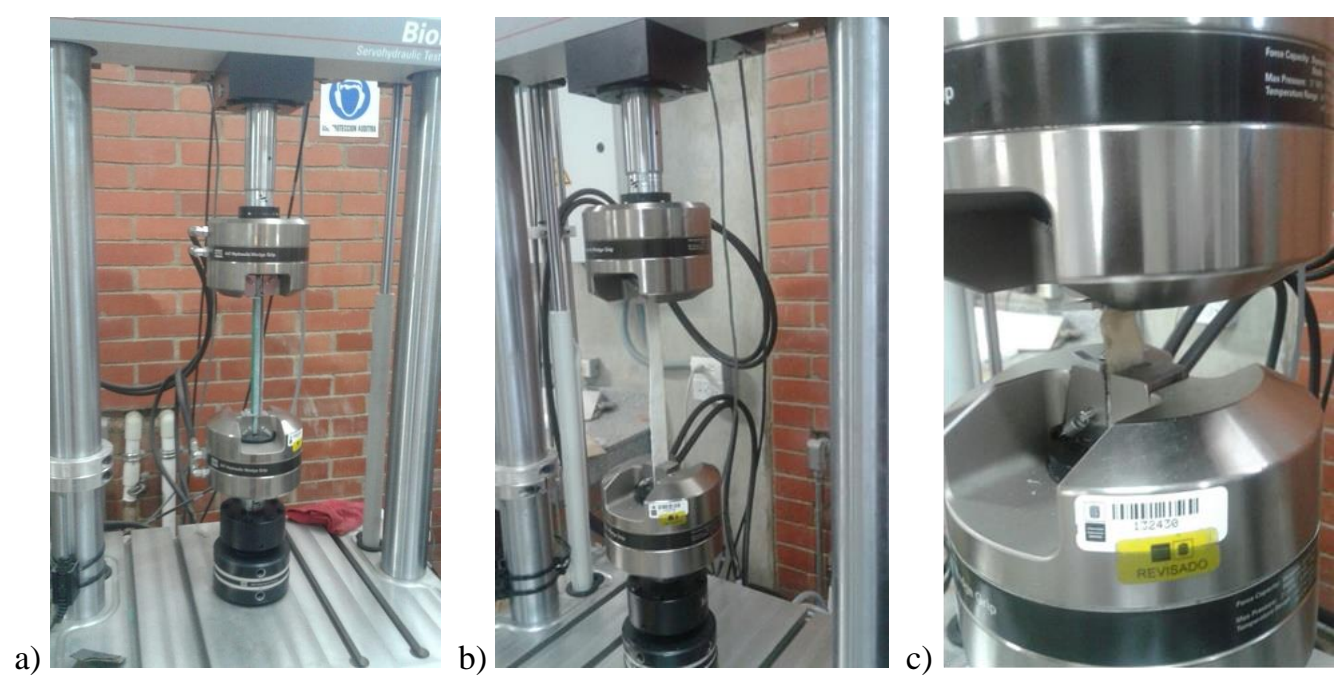

Figure 1. a) Tensile test on a commercial pipe, b) tension on hand laid-up specimen, c) compression on hand laid-up specimen.

\section{Validation and results}

We define a numerical model for the multilayer composite pipe using the finite element method. Material properties of the pipe are shown in Table 1.

Table 1. Material properties for the layers of the composite pipe.

\begin{tabular}{|c|c|c|c|c|c|c|c|c|c|}
\hline \multirow[b]{2}{*}{ Layer } & \multicolumn{3}{|c|}{ Young's Modulus } & \multicolumn{3}{|c|}{ Poisson Ratio } & \multicolumn{3}{|c|}{ Shear Modulus } \\
\hline & $\begin{array}{c}\mathrm{E} 1 \\
{[\mathrm{MPa}]}\end{array}$ & $\begin{array}{c}\mathrm{E} 2 \\
{[\mathrm{MPa}]}\end{array}$ & $\begin{array}{c}\mathrm{E} 3 \\
{[\mathrm{MPa}]}\end{array}$ & $v 12$ & $v 23$ & $v 13$ & $\begin{array}{c}\mathrm{G} 12 \\
{[\mathrm{MPa}]}\end{array}$ & $\begin{array}{c}\mathrm{G} 23 \\
{[\mathrm{MPa}]}\end{array}$ & $\begin{array}{c}\mathrm{G} 13 \\
{[\mathrm{MPa}]}\end{array}$ \\
\hline Interior HDPE & 1,340 & I & I & 0.4 & / & / & 478.5 & / & I \\
\hline $\begin{array}{l}\text { Epoxy-glass } \\
\text { fiber laminate }\end{array}$ & 35,000 & 9,000 & 9,000 & 0.28 & 0.4 & 0.28 & 4,700 & 3,500 & 4,700 \\
\hline Exterior HDPE & 1,340 & / & / & 0.4 & / & / & 478.5 & / & / \\
\hline
\end{tabular}

For the model, we use the following stress limits: tensile in X, 780 [MPa], tensile in $\mathrm{Y}, 31$ [MPa], compressive in $\mathrm{X}, 480$ [MPa], compressive in Y, 100 [MPa], shear in YZ, 35 [MPa] and shear in other directions, 60 [MPa]. A nominal internal pressure load of $5 \mathrm{MPa}$ was applied, considering the three different boundary condition. The stresses across the thickness were obtained, stresses do not change with the theta or $\mathrm{Z}$ coordinate [14]. The axial stress distribution was plotted with respect to a dimensional radius defined with respect to the outer and inner radius as $\mathrm{R}=(\mathrm{r}-\mathrm{rint}) /($ rout-rint). 
Figure 2 shows the axial stress distribution with respect to the boundary condition. Note that axial stress varies with the thickness, with higher values at the stiffer reinforcing layer, as expected. The highest axial stress is for the closed-end condition and the lowest value for the open-end. For the three boundary conditions tested, the hoop stress distribution shows the same value [14]. These results are in agreement with those presented by Xia et al. [4].

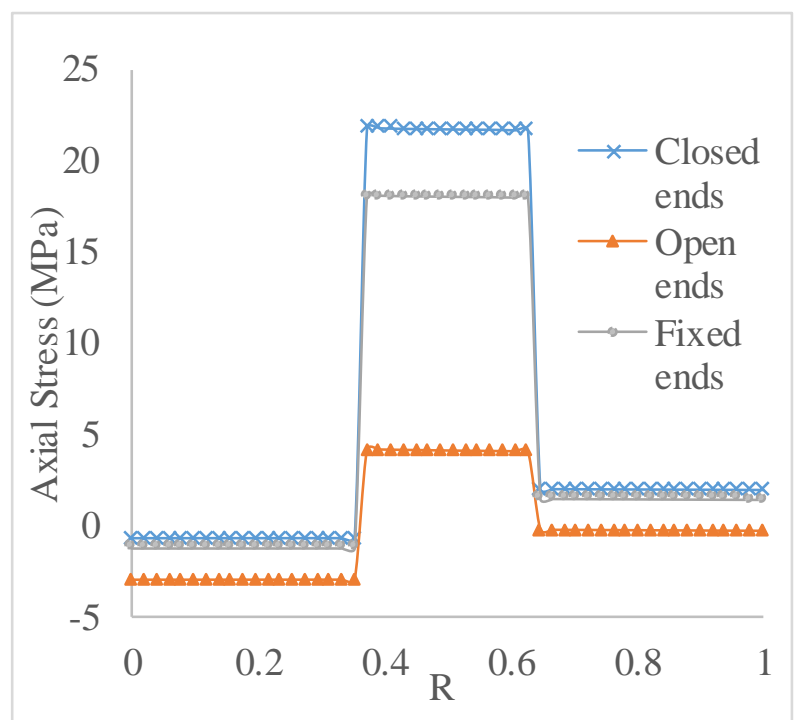

Figure 2. Axial stress distribution along the thickness

Once the stress and strain fields are obtained, it is possible to apply a failure criterion to determine the first ply failure. Thus, the load was increased until the FPF pressure was obtained according to three different failure criteria, shown in Table 2.

Table 2. FPF for different BC using different failure criteria.

\begin{tabular}{cccc}
\hline & $\begin{array}{c}\text { Open-end } \\
{[\mathrm{MPa}]}\end{array}$ & $\begin{array}{c}\text { Fixed-end } \\
{[\mathrm{MPa}]}\end{array}$ & $\begin{array}{c}\text { Closed-end } \\
{[\mathrm{MPa}]}\end{array}$ \\
\hline Max. stress & 13.73 & 11.15 & 9.25 \\
Tsai-Hill & 10.94 & 9.96 & 8.62 \\
Hashin & 11.06 & 10.04 & 8.68 \\
\hline
\end{tabular}

From that point, the progressive damage analysis initiates, using load steps, and the solution for each incremental step is obtained and the stresses, strains and damage status of each layer is found. The values of the damage parameters used were: energy dissipated per unit area for tensile damage 490 $[\mathrm{N} / \mathrm{mm}]$, for compressive fibre damage $10[\mathrm{~N} / \mathrm{mm}]$, and for matrix $11[\mathrm{~N} / \mathrm{mm}]$. All the viscous regularization variables were set to 0.01 .

Figure 3 shows the stress distribution for the first layer of a closed end condition, for two different values of pressure: $8 \mathrm{MPa}$ and $12 \mathrm{MPa}$. The stress distribution tends to concentrate at the edges, which is in agreement with the work of Baranger et al. [15]. This non-uniform stress distribution at the edges propagates to other layers and, for higher loads, we even find more non-uniform stress distributions, as shown in Figure 4 for the most external HDPE layer at a load of $15 \mathrm{MPa}$. The burst strength was found numerically to be $22[\mathrm{MPa}]$, which is the point when a single thickness point fails in all the layers, whereas the experimental burst strength is 27 [MPa]. 


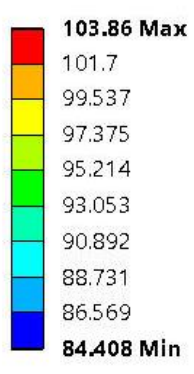

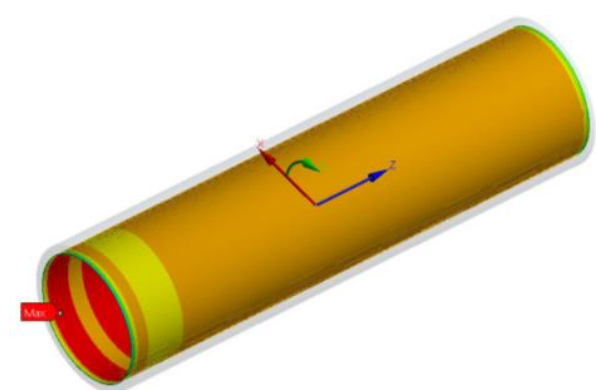

a)

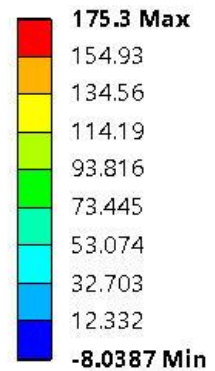

$-8.0387 \mathrm{Min}$

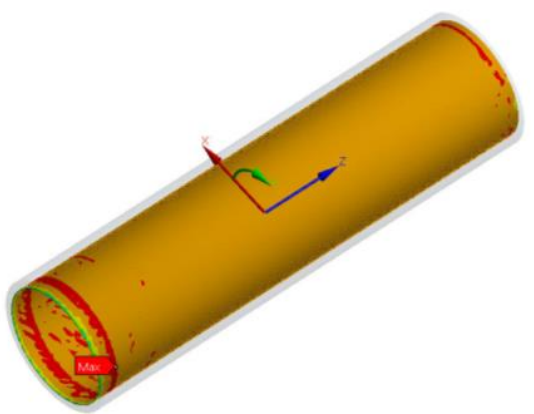

b)

Figure 3. Hoop stress distribution of the first layer for: a) 8MPa, and b) $12 \mathrm{MPa}$.

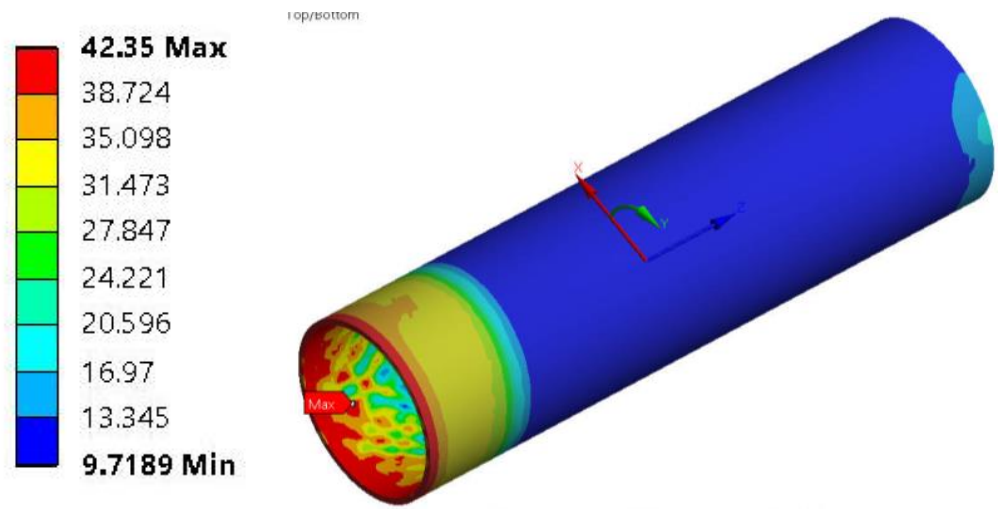

Figure 4. Hoop stress distribution of HDPE outer layer.

\section{Conclusions}

This model is a useful tool in the assessment of the remaining life of composite pipes. Under real conditions, damage can be locally initiated due to different events such as impacts, earthquakes, thermal distortion or interaction with the environment, this damage can be measured and evaluated using the above-mentioned method.

The model for the multilayer composite pipe was numerically defined. Interest was given in the definition of the fibre reinforced layer, and the model was validated through experimental tests. It was shown that the FPF pressure for the open-end or pure internal pressure condition was the highest.

The damage progression initiates near the boundary conditions on the cross sections, and propagates towards the centre of the pipe. This damage can lead to delamination which is not considered in this study. The stiffness degradation causes an irregular stress distribution that propagates to different layers. Matrix cracking is the most critical mechanism of damage in composite pipes.

The functional failure predicted by the open-end condition is near $22 \mathrm{MPa}$ (the point at which an element in all layers has failed). The experimental burst strength pressure was about $27 \mathrm{MPa}$. Differences can be accounted to the fact that, for the burst strength, an entire region must fail.

\section{References}

[1] A. Sas-Jaworsky, J. G. Williams, A. Sas-Jaworsky, and J. G. Williams, "Composite Spoolable Pipe Development , Advancements , and Limitations," in Offshore Technology Conference, 2000. 
[2] S. Gómez, B. Ramón, and R. Guzman, "Comparative study of the mechanical and vibratory properties of a composite reinforced with fique fibers versus a composite with E-glass fibers," Rev. UIS Ing., vol. 17, no. 1, pp. 43-50, 2018.

[3] R. K. Watkins and L. R. Anderson, Structural Mechanics of Buried Pipes. Boca Ratón, Florida: CRC Press, 1999.

[4] M. Xia, H. Takayanagi, and K. Kemmochi, "Analysis of multi-layered filament-wound composite pipes under internal pressure," Compos. Struct., vol. 53, no. 4, pp. 483-491, 2001.

[5] X. S. Sun, V. B. C. Tan, Y. Chen, L. B. Tan, R. K. Jaiman, and T. E. Tay, "Stress analysis of multi-layered hollow anisotropic composite cylindrical structures using the homogenization method," Acta Mech., vol. 225, no. 6, pp. 1649-1672, 2014.

[6] H. G. Kunert, J. L. Otegui, and A. Marquez, "Nonlinear FEM strategies for modeling pipe-soil interaction," Eng. Fail. Anal., vol. 24, pp. 46-56, 2012.

[7] X. Anping, S. Peng, Z. Jingjing, and Q. Yunxia, "FEA-based Comparison of Two Kinds of Steel Wire Reinforced Composite Pipes," 4th Int. Conf. Intell. Networks Intell. Syst., pp. 184$187,2011$.

[8] L. Ferry, D. Perreux, J. Rousseau, and F. Richard, "Interaction between plasticity and damage in the behaviour of $[+\varphi,-\varphi] n$ fibre reinforced composite pipes in biaxial loading (internal pressure and tension)," Compos. Part B Eng., vol. 29, pp. 715-723, 1998.

[9] P. F. Liu, L. J. Xing, and J. Y. Zheng, "Failure analysis of carbon fiber/epoxy composite cylindrical laminates using explicit finite element method," Compos. Part B Eng., vol. 56, pp. 54-61, 2014.

[10] J. H. S. Almeida, M. L. Ribeiro, V. Tita, and S. C. Amico, "Damage and failure in carbon/epoxy filament wound composite tubes under external pressure: Experimental and numerical approaches," Mater. Des., vol. 96, pp. 431-438, 2016.

[11] Z. Hashin, "Failure Criteria for Unidirectional Fiber Composites," J. Appl. Mech., vol. 47, no. 2, p. 329, 1980.

[12] E. J. Barbero, Finite Element Analysis of Composite Materials Using ANSYS, Second. Boca Raton, U.S.A.: CRC Press, 2013.

[13] A. Matzenmiller, J. Lubliner, and R. L. Taylor, "A constitutive model for anisotropic damage in fiber-composites," Mech. Mater., vol. 20, no. 2, pp. 125-152, 1995.

[14] O. A. González-Estrada, J. Leal-Enciso, J. D. Reyes-Herrera, J. Leal Enciso, and J. D. Reyes Herrera, "Análisis de integridad estructural de tuberías de material compuesto para el transporte de hidrocarburos por elementos finitos," Rev. UIS Ing., vol. 15, no. 2, pp. 105-116, Jan. 2016.

[15] E. Baranger, O. Allix, and L. Blanchard, "A computational strategy for the analysis of damage in composite pipes,” Compos. Sci. Technol., vol. 69, no. 1, pp. 88-92, 2009. 